\section{Internal and Marginal Fit and Fracture Strength of Narrow Diameter Dental Implant-Abutment Assembly}

George Hebert Ruschel ${ }^{1} \odot$, Atais Bacchi²@ Izabela Cristina Maurício Moris ${ }^{1}{ }^{\circledR}$, Stephanie Francoi Poole ${ }^{1}\left[\right.$, Ricardo Faria Ribeiro ${ }^{3}{ }^{\circledR}$, Érica Alves Gomes ${ }^{1}{ }^{\circledR}$
'School of Dentistry, UNAERP - Universidade de Ribeirão, Ribeirão Preto, SP, Brazil ${ }^{2}$ IMED - Faculdade Meridional, Passo Fundo, RS, Brazil ${ }^{3}$ Department of Prosthodontics and Dental Materials, Dental School of Ribeirão Preto, USP - Universidade de São Paulo, Ribeirão Preto, SP, Brazil

Correspondance: Profa. Dra. Érica Alves Gomes, Avenida Costábile Romano, 2.201, 14096-900 Ribeirão Preto, SP, Brasil. Tel.: + 55-16-3603-7000. e-mail: ericaagomes@yahoo.com.br
Key Words: abutments, cyclical loading, dental implants, fit.

\section{e-mail: ericaagomes@yahoo.com.br}

\begin{abstract}
The aim of this study was to assess the internal and vertical marginal fit of metallic copings to abutments and the fracture strength of different narrow diameter dental implant/ abutments, either submitted to thermomechanical cycling or not. Sixty-four implant/ abutments $(n=16)$ were divided into 4 groups according to diameter and abutment type: G3.5-UAC (morse taper implant $\emptyset 3.5 \mathrm{~mm}+$ universal abutment with beveled chamfer finish); G2.9-UAS (morse taper implant $\emptyset 2.9 \mathrm{~mm}+$ universal abutment with shoulder finish); G2.8-AA (morse taper friction implant $\emptyset 2.8 \mathrm{~mm}$ + anatomical abutment) and G2.5-HP (one-piece implant $\emptyset 2.5 \mathrm{~mm}$ with indexed hexagonal platform). Each group was divided into two subgroups $(\mathrm{n}=8)$ : submitted and not submitted to thermomechanical cycling (TMC). To assess internal and vertical marginal fit of metallic copings, the assemblies were scanned using microtomography $($ micro-CT) $(n=5)$. The samples were subjected to the compressive strength test on a universal test machine. Group G3.5-UAC showed the highest marginal misfit regardless of TMC $(p<0.05)$. All other groups were similar after TMC. Group G2.8-AA showed the lowest internal misfit both with and without TMC $(p<0.05)$. Group G2.8-AA showed the highest fracture strength, similar only to G2.5-HP without TMC and G3.5-UAC with TMC. The type of abutment affects the internal and marginal fit of metallic copings and the anatomical abutment led to the best internal and marginal coping fit. The narrow diameter dental implant/abutments differ in terms of fracture strength, the strongest assembly was that composed by implant of type $V$ grade titanium without internal threads (friction implant).
\end{abstract}

\section{Introduction}

Narrow-diameter implants have become a common choice in Dentistry because they can be used as an alternative for rehabilitation of areas with significant bone resorption after dental extraction, regions with bone loss following periodontal disease, trauma or dental agenesis, reduced mesiodistal prosthetic space, or limited interradicular space (1). Narrow-diameter implants can avoid the use of bone grafts, leading to reduced treatment time, cost, and morbidity (1).

However, some disadvantages of the use of narrowdiameter implants have been observed. Regarding the biomechanical behavior, the narrow-diameter implant is less structurally resistant than regular implants (with a diameter larger than $3.5 \mathrm{~mm})(2,3)$. In addition to that, narrow-diameter implants have a small surface area, with reduced bone-implant contact. This could affect the stress distribution on the bone, potentially compromising the osseointegration $(4,5)$.

Biomechanical properties have shown significant improvement associated with the use of implants with tapered connections (6). The characteristics of the implant/ abutment interface of narrow-diameter implants can also affect the mechanical behavior of the system (3). One-piece narrow-diameter implants are also available (1). Comparing different narrow-diameter implants commercially available, some authors point out that one-piece implants present decreased peri-implant bone resorption due to the lack of a micro-gap between implant and abutment, which have been associated with micro-infiltration and bacterial infection, which could be potentialized by the conjunct deformation (7). On the other hand, two-pieces narrowdiameter implants have shown high rates of mechanical failures, such as fractures of prosthetic abutment and screw loosening (7). Nonetheless, some studies have shown favorable biomechanical results with the use of narrowdiameter implants $(8,9)$.

The clinical success of rehabilitations using implantsupported prosthesis is directly linked to a passive fit between crown and prosthetic abutment $(10,11)$. The passive fit of an implant-supported prosthetic structure is defined as a stress-free circular contact at the abutment/prosthesis interface before functional loading (12). This is key to keep the mechanical and biological balance, and to reduce load 
on abutment, screw, and bone $(13,14)$, since an excellent internal adaptation facilitates the prosthetic crown fitting without compromising its resistance and retention.

In narrow-diameter implants, a poor marginal adaptation contributes to bacterial growth and inflammatory reactions on the peri-implant area (11), which favors bone loss (15). Therefore, it is also important that marginal adaptation is maintained after occlusal loading. The clinically acceptable marginal misfit varies in different studies $(14,16)$, but it is a consensus that it should be no higher than 100-150 $\mu \mathrm{m}(14,16)$.

Currently, several types of narrow-diameter implants are commercially available varying in connection type, macrostructure, material, diameter, and presence or absence of a prosthetic abutment (implant/abutment or onepiece implant). In addition to that, a comparison among systems with different implant/abutment assemblies is not stablished in literature.

This study aimed to assess internal and vertical marginal fit of metal copings cemented on different abutments and the fracture strength of the implant/abutment narrowdiameter implant assemblies. The null hypotheses assume that (I) there are no differences in internal and marginal

fit, and (II) there are no differences in fracture strength.

\section{Material and Methods}

The experiment used 64 implants measuring $13 \mathrm{~mm}$ in length and their respective abutments for cementedretained crowns. The implants were divided into four groups ( $n=16)$, as described in Table 1. Details of each implant/abutment are shown in Figure 1. The abutments in groups G3.5-UAC and G2.9-UAS were installed using torque of $20 \mathrm{~N} . \mathrm{cm}$ and $15 \mathrm{~N} . \mathrm{cm}$, respectively, according to the manufacturer's recommendations. In group G2.8-AA, the anatomical taper was coupled using a proper hammer. In group G2.5-HP, because it is a one-piece implant, the hexagonal abutment is coupled to the implant as default; thus, only a short extension screw was used to attach the prosthetic crown, which was installed with 20 N.cm of torque. The prosthetic abutments transmucosal height was standardized in $1.5 \mathrm{~mm}$.

\section{Manufacturing of the Metal Copings}

Cast components specific for each system were used for the copings manufacturing. The G2.8-AA, that lacks a cast component, was directly waxed. The resulting anatomy was compatible with that of a coping for maxillary lateral incisors, standardized with a bipartite condensing silicone matrix (Zetaplus, Zhermack, Badia Polesine, Rovigo, Italy).

After waxing, the crowns were coated (Heat Shock, Polidental Ind. e Com. Ltda, Cotia, SP, Brazil) and cast in chromium-cobalt alloy (Fit Cast Cobalto, Talmax, Curitiba, $\mathrm{PR}$, Brazil) through the lost-wax process. All copings were sandblasted with aluminum oxide particles (Polidental Ind. e Com. Ltda, Cotia, SP, Brazil), with $100 \mu \mathrm{m}$ grit, to remove any coating residues. Then, the copings were finished and polished with appropriate tips and pastes for the metal

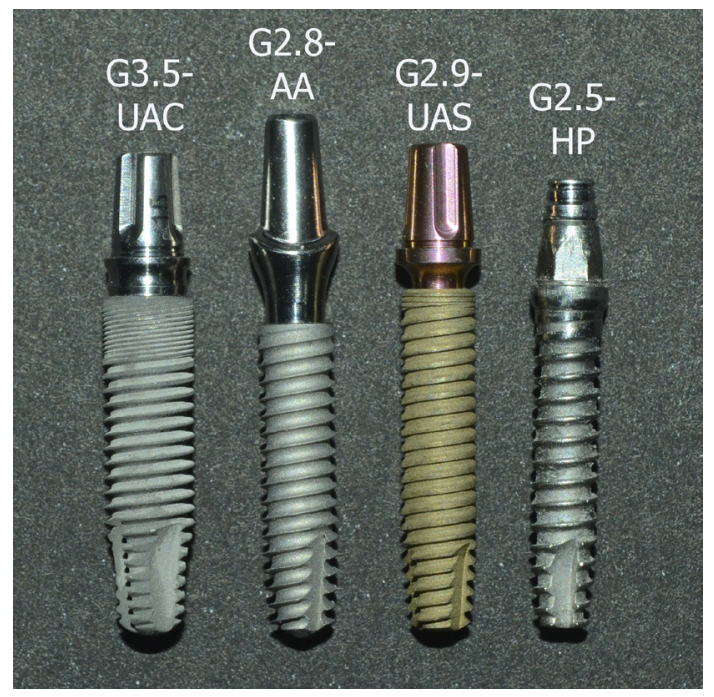

Figure 1. specimens used in the study

Table 1. Experimental groups

\begin{tabular}{|c|c|c|c|c|c|}
\hline Groups & Implant & Dimensions & Plataform & Abutment & Manufacturer \\
\hline G3.5- UAC & $\begin{array}{c}\text { Implant } \\
\text { Titamax } \\
\text { GranMorse }\end{array}$ & $\begin{array}{c}\emptyset 3.5 \times \\
13.0 \mathrm{~mm}\end{array}$ & Tappered & $\begin{array}{l}\text { UAC) Universal abutment GM exact ( } 3.3 \\
\text { x } 6.0 \mathrm{~mm} \text { ), with beveled chamfer finish }\end{array}$ & Neodent, Curitiba, PR, Brazil \\
\hline G2.8- AA & Implant Facility & $\begin{array}{c}\emptyset 2.8 \times \\
13.0 \mathrm{~mm}\end{array}$ & $\begin{array}{l}\text { Tappered } \\
\text { friction }\end{array}$ & $\begin{array}{l}\text { AA) Anatomical abutment } \\
\text { facility }(2.5 \times 6.5 \mathrm{~mm})\end{array}$ & Neodent, Curitiba, PR, Brazil \\
\hline G2.9- UAS & $\begin{array}{c}\text { Implant } \\
\text { Morse taper } \\
\text { Unitite Slim }\end{array}$ & $\begin{array}{c}\emptyset 2.9 \times \\
13.0 \mathrm{~mm}\end{array}$ & Tappered & $\begin{array}{l}\text { UAS) Universal abutment ( } 3.3 \mathrm{x} \\
6.0 \mathrm{~mm} \text { ) with shoulder finish }\end{array}$ & $\begin{array}{l}\text { SIN Sistema de Implantes, } \\
\text { São Paulo, SP, Brazil }\end{array}$ \\
\hline G2.5-HP & $\begin{array}{l}\text { One-piece } \\
\text { Implants Mini } \\
\text { FlexCone }\end{array}$ & $\begin{array}{c}\emptyset 2.5 \times \\
13.0 \mathrm{~mm}\end{array}$ & $\begin{array}{l}\text { One-piece } \\
\text { Hexagonal }\end{array}$ & $\begin{array}{l}\text { HP) One-piece implant hexagonal platform } \\
(2.6 \mathrm{~mm} \times 4 \mathrm{~mm}) \text { with extension screw }\end{array}$ & $\begin{array}{l}\text { DSP Biomedical, Campo } \\
\text { Largo, PR, Brazil }\end{array}$ \\
\hline
\end{tabular}


(Exa-Cerapol, Edenta, Au/SG, Switzerland).

The cementation process was performed with dual polymerization resin cement (Allcem Core, FGM, Joinville, SC, Brazil), according to the manufacturer's recommendations, using $250 \mathrm{~g}$ of pressure. Cement was photoactivated for $40 \mathrm{~s}$ at the interface coping/abutment at $1200 \mathrm{~mW} / \mathrm{cm}^{2}$. Cement excesses were removed using finishing tips adequate for the specific material (ExaCerapol, Edenta, Au/SG, Switzerland).

The implant/abutment/coping assemblies were inserted into PVC cylinders containing epoxy resin (Resina F23, Axson, Cergy, France) at 30 angle, as per ISO 14801 (17).

\section{Internal and Vertical Marginal Misfit Assessment Using Computer Microtomography (Micro-Ct)}

The marginal adaptation of coping/abutment assemblies was assessed using micro-CT (SkyScan 1176, Bruker, microCT, Kontich, Belgium). Eight sets of each group were scanned using the following parameters: acceleration strength of 90 $\mathrm{kV}$, current of $272 \mathrm{~mA}$, rotation of $360^{\circ}$, isotropic resolution of $9 \mu \mathrm{m}$, rotation steps of 0.7 , frames of 4 , and Copper filter of $0.1 \mathrm{~mm}$. The micro-CT images were reconstructed using the software NRecon (Bruker-microCT, Kontich, Belgium) with the following image fitting parameters: Smoothing $=4$; Ring Artifact Correction=20; Beam Hardening Correction $(\%)=51$.

Image processing and analysis were initially performed using the software Data Viewer (Bruker, micro-CT, Kontich, Belgium) that allows the simultaneous visualization of the three axes $(x, y, z)$. From this visualization, two new files were derived for the analysis of internal and marginal misfit with the software CTAn (Bruker, micro-CT, Kontich, Belgium): (1) New folder of sagittal views; (2) New folder of coronal views.

The new folders (sagittal and coronal) were uploaded to CTAn where the internal and marginal fit were measured using the Measure Tool in 10 different sections of each plane. To this end, the implant/abutment/coping central slice (coronal and sagittal) was defined in each folder, plus five slices above and five slices below the central one, with a step of $0.100 \mathrm{~mm}$. Thus, for each condition, two measurements for vertical marginal misfit and two measurements for internal misfit were taken on each face (vestibular, palatal, mesial, and distal), resulting in 20 measurements per face, and 80 measurements per specimen.

\section{Thermomechanical Cycling Test (TMC)}

The TMC was performed on 32 samples, eight from each of the four groups, in a pneumatic load simulator (BIOPDI, São Carlos, SP, Brazil). The samples were placed in the test machine where each assembly was subjected to a load of $100 \mathrm{~N}$ using a flat surface metal tip on the cingulum region of the metal crown. The test simulated 1 year of prosthetic crown use, which corresponds to $1 \times 106$ mechanical cycles of $3 \mathrm{~Hz}$ (17). During the test, all samples were kept in distilled water and submitted to approximately 2000 thermal cycles in the temperature range of $5^{\circ}-55^{\circ} \mathrm{C}(18)$.

After the thermomechanical cycling test, the samples were scanned, as previously described, and the internal and vertical marginal fit of the copings were assessed.

\section{Compressive Strength Test}

The samples were attached to a metal device in the mechanical universal test machine (Biopdi, São Carlos, Brazil), with a load cell of $1,000 \mathrm{kgf}$, and crosshead speed of $1.0 \mathrm{~mm} / \mathrm{min}$. The load was applied on the coping's palatal concavity until exceeding the maximum deformation force (MDF) and plastic deformations occur, or until fracture of one of the components. As a rule, if the displacement reached $3 \mathrm{~mm}$ without deformation, the test was discontinued. Values of maximum deformation force and fracture force were analyzed. Samples randomly chosen from each subgroup were taken to micro-CT qualitative analysis after the test.

\section{Statistical Analysis}

Shapiro-Wilk's normality test and Levene's homogeneity test showed that the data were normally distributed. Internal and vertical marginal misfit and compressive strength were analyzed with linear mixed models and Tukey's post hoc test $(p<0.05)$. The analyses were performed using the SPSS software (IBM SPSS Statistics, v20.0; IBM Corp.).

\section{Results}

\section{Vertical Marginal Misfit}

Table 2 shows coping/abutment vertical marginal misfit. There was significant difference between groups in different times. Among groups without TMC, G3.5-UAC showed the highest misfit, significantly different from all other groups $(p<0.05)$. G2.5-HP showed a higher misfit than G2.9-UAS and G2.8-AA. With TMC, only G3.5-UAC was significant different, with higher misfit values.

TMC shows no effect on intragroup vertical marginal misfit of copings/abutments ( $p>0.05$ ). Qualitative analysis of micro-CT images (Fig. 2) showed the highest loss of material between the coping finish and the prosthetic abutment's platform in group G3.5-UAC.

\section{Internal Misfit}

Table 3 shows the internal marginal misfit between coping and abutment. Groups G3.5-UAC and G2.5-HP without TMC showed no statistical difference from each other, but present internal marginal misfit significantly 
higher than the other groups ( $\mathrm{p}<0.05)$. G2.9-UAS presented misfit results significantly higher than 2.8-AA $(p<0.05)$. With TMC, only G2.8-AA presented results significantly lower than the other groups (G3.5-UAC, G2.9-UAS and G2.5-HP) ( $p<0.05)$, which showed no difference from each other $(p>0.05)$.

TMC significantly reduced the internal marginal misfit of

Table 2. Groups, average, and standard deviation (SD) of vertical marginal misfit $(\mu \mathrm{m})$.

\begin{tabular}{lccccc}
\hline Groups & Aging & Average & SD & Minimum & Maximum \\
\hline \multirow{2}{*}{ G3.5-UAC } & None & $195.2 \mathrm{Aa}$ & 8.8 & 187.2 & 197.1 \\
& TMC & $165.8 \mathrm{Aa}$ & 10.2 & 132.9 & 198.7 \\
\multirow{2}{*}{ G2.9-UAS } & None & $64.5 \mathrm{Ca}$ & 9.2 & 59.6 & 69.5 \\
& TMC & $48.2 \mathrm{Ba}$ & 2.6 & 15.4 & 81.1 \\
\multirow{2}{*}{ G2.8-AA } & None & $67.3 \mathrm{Ca}$ & 6.3 & 62.3 & 72.3 \\
& TMC & $66.1 \mathrm{Ba}$ & 6.9 & 33.2 & 99.0 \\
G2.5-HP & None & $83.6 \mathrm{Ba}$ & 5.9 & 78.7 & 88.6 \\
& TMC & $65.7 \mathrm{Ba}$ & 14.2 & 32.8 & 98.6 \\
\hline
\end{tabular}

Different uppercase letters indicate statistical difference between groups ( $\mathrm{p} \leq 0.05)$, and different lowercase letters indicate statistical difference within groups (comparing groups with and without TMC) copings/abutments of groups G3.5-UAC, G2.8-AA and G2.5HP $(p<0.05)$ (Table 3). Qualitatively, all groups presented a similar pattern of internal marginal misfit, with higher misfit close to the coping finish line (Fig. 3).

\section{Compressive Strength}

Table 4 shows the compressive strength of the implant/

Table 3. Groups, averages, and standard deviation (SD) of internal marginal misfit $(\mu \mathrm{m})$

\begin{tabular}{lccccc}
\hline Groups & Aging & Average & SD & Minimum & Maximum \\
\hline \multirow{2}{*}{ G3.5-UAC } & None & $182.6 \mathrm{Aa}$ & 8.7 & 176.3 & 189.0 \\
& TMC & $152.5 \mathrm{Ab}$ & 7.0 & 145.7 & 159.3 \\
\multirow{2}{*}{ G2.9-UAS } & None & $146.5 \mathrm{Ba}$ & 10.6 & 140.1 & 152.9 \\
& TMC & $144.6 \mathrm{Aa}$ & 9.3 & 137.8 & 151.3 \\
\multirow{4}{*}{ G2.8-AA } & None & $120.4 \mathrm{Ca}$ & 10.7 & 114.0 & 126.8 \\
& TMC & $88.2 \mathrm{Bb}$ & 13.5 & 81.5 & 95.0 \\
\multirow{2}{*}{ G2.5-HP } & None & $193.2 \mathrm{Aa}$ & 9.5 & 186.8 & 199.6 \\
& TMC & $154.8 \mathrm{Ab}$ & 11.2 & 148.0 & 161.6 \\
\hline
\end{tabular}

Different uppercase letters indicate statistical difference between groups ( $\mathrm{p} \leq 0.05)$, and different lowercase letters indicate statistical difference within groups (comparing groups with and without TMC) $(\mathrm{p} \leq 0.05)$.
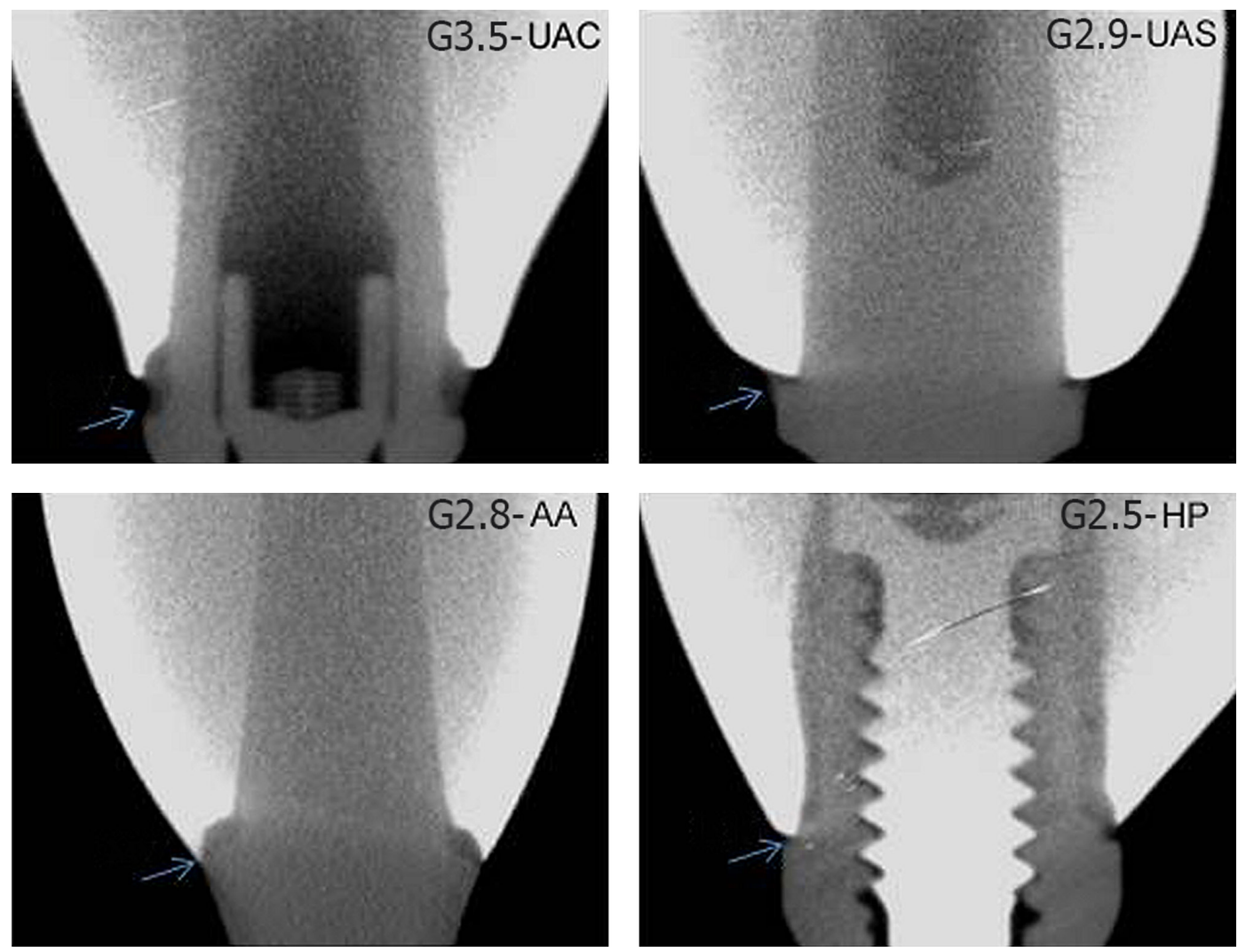

Figure 2. micro-CT representative images of vertical marginal misfit. 
abutment/coping assemblies. Among those without TMC, G2.8-AA presented the highest values, lacking statistical difference only from group G2.5-HP. Groups G3.5-UAC and G2.5-HP were similar. G2.9-UAS presented the lowest results $(p<0.05)$. With TMC, $62.8-A A$ presented the highest values, lacking statistical difference only from G3.5-UAC. Groups G2.5-HP and G2.9-UAS showed the lowest values and lack statistical difference from each other.

TMC affected the compressive strength only of group

Table 4. Groups, averages, and standard deviation (SD) of compressive strength $(\mathrm{N})$

\begin{tabular}{lccccc}
\hline Groups & Aging & Average & SD & Minimum & Maximum \\
\hline G3.5- & None & $516.2 \mathrm{Ba}$ & 93.1 & 443.5 & 588.9 \\
UAC & TMC & $462.8 \mathrm{Aba}$ & 105.9 & 389.4 & 536.1 \\
G2.9- & None & $343.4 \mathrm{Ca}$ & 39.4 & 270.8 & 416.1 \\
UAS & TMC & $331.4 \mathrm{Ba}$ & 58.6 & 258.1 & 404.8 \\
G2.8- & None & $681.1 \mathrm{Aa}$ & 150.1 & 608.4 & 753.8 \\
AA & TMC & $603.0 \mathrm{Aa}$ & 142.4 & 529.6 & 676.3 \\
G2.5- & None & $544.0 \mathrm{ABa}$ & 86.6 & 471.4 & 616.7 \\
HP & TMC & $341.6 \mathrm{Bb}$ & 78.0 & 268.2 & 414.9 \\
\hline
\end{tabular}

Different uppercase letters indicate statistical difference between groups $(\mathrm{p} \leq 0.05)$, and different lowercase letters indicate statistical difference within groups (comparing groups with and without TMC) $(\mathrm{p} \leq 0.05)$.

\section{G2.5-HP $(\mathrm{p}<0.05)$ (Table 4).}

Figure 4 shows the micro-CT failure mode, where it was possible to observe that plastic deformation of the assemblies occurred before the tests for all groups, both with and without TMC. It was also possible to observe a displacement of the prosthetic crown as a result of the applied load. Fractures were observed in groups G3.5-UAC and G2.5-HP.

\section{Discussion}

This study assessed the internal and vertical marginal misfit, and the compressive strength of coping/abutment/ implant assemblies, both with and without TMC. The assemblies were also qualitatively assessed through microCT. The first null hypothesis was rejected, since differences in internal and marginal misfit were observed.

Regarding the acceptable vertical marginal misfit values at the interface between coping and abutment, Branemark (13) stated values of $10 \mu \mathrm{m}$. Currently, most of studies consider marginal discrepancies of up to 100-150 $\mu \mathrm{m}$ as clinically acceptable $(14,16,20)$. In the present study, only G3.5-UAC showed misfit values above these clinically acceptable values (with and without TMC), which might be related to the abutment design that can hinder the coping accommodation due to its higher level of details (Fig. 1).
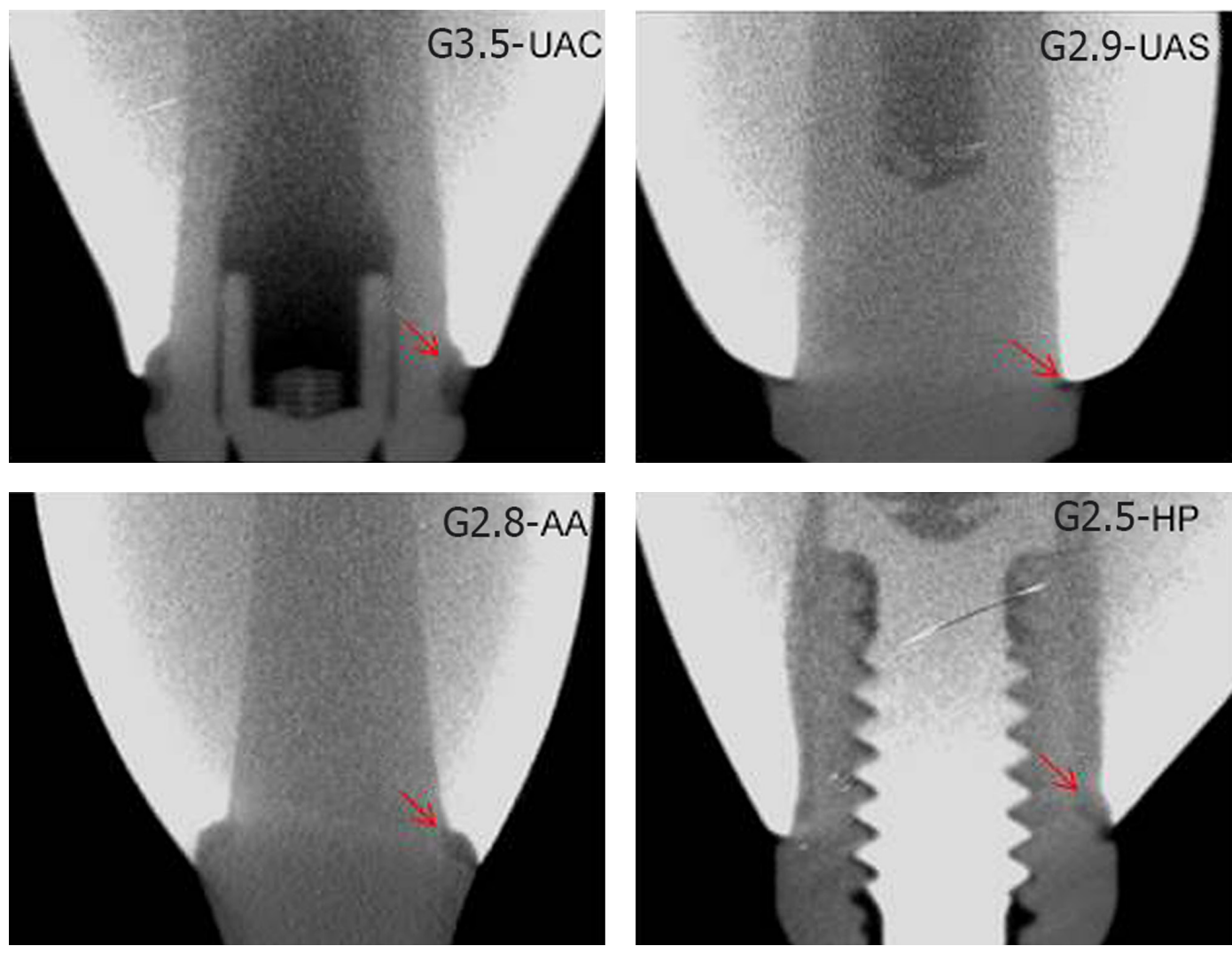

Figure 3. micro-CT representative images of horizontal marginal misfit 
Crevices on the abutment and screw access hole can be more critical due to the intrinsically distortions during casting. Compared with group G2.9-UAS, the higher misfit values observed in G3.5-UAC can be attributed to the fact that the coping adaptation in beveled chamfer finish structures can to be more critical than in the shouldered ones.

Groups G3.5-UAC and 2.5-HP, which have more detailed abutments with crevices and retentions (Fig. 1), showed the highest internal marginal misfit. On the other hand, G2.8$A A$, which prosthetic abutment is flat and lacks any details on the surface, had the best results, which can be linked to a fewer interference of the prosthetic cylinder and minor dimensional changes caused during the casting process. Misfit may interfere with the proper accommodation of the prosthetic crown to the abutment platform, affecting the assembly's stability (20-22). All groups showed high internal marginal misfit of the coping/abutment (both with and without TMC). The conventional casting using the lost-wax process associated with the fully cast cylinders may have negatively affected the crowns adaptation to the abutments because the casting process might have caused a dimensional change of the castable cylinder, particularly in group 3.5-UAC, which abutment is more detailed on the surface. The use of castable cylinders with a metal band (currently not commercially available in the systems adopted in this study) could minimize this effect. In these cases, the metal is less susceptible to changes due to the casting process because its temperature of fusion is above the firing temperature of the coating and compatible with the alloy injection temperature (23). Hence, it could maintain the waxing standardized dimensions without higher distortions on the prosthetic coping basis. Another solution would be designing the crowns in CAD/CAM system because this digital technology is able to produce more precise and adapted pieces if compared with conventional methods $(19,22,24)$.

This study showed that TMC significantly reduced only internal misfit, corroborating previous findings $(21,25)$ that showed that the accommodation of prostheses to the prosthetic abutments suffer changes over time after
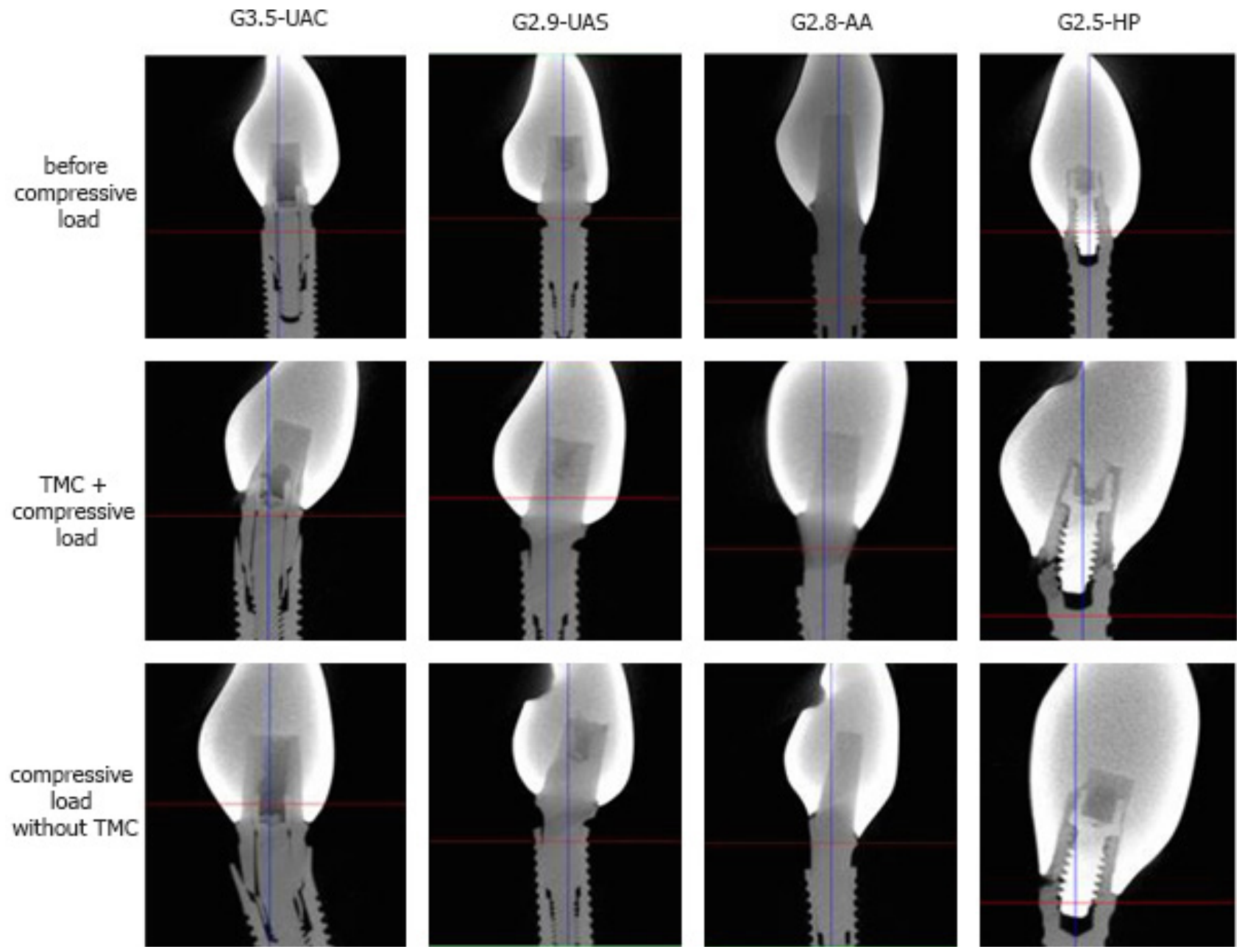

Figure 4. micro-CT representative imagens of failure mode after compressive load 
the mechanical loading. This is because misfit between abutment and crown can be diminished after loading due to wearing of the interfaces between components, and this can eliminate micro-interferences derived from the machining process, bringing them closer and reducing misfit (21).

The second null hypothesis is also rejected since it was observed differences in the assemblies' resistance to fracture. There was no direct relation between resistance and diameter of the implants, since group G2.8-AA presented larger compressive strength than the other groups. Group G3.5-UAC showed lower compressive strength than groups G2.8-AA and G2.5-HP, with and without TMC. Thus, the choice of implants and abutments should consider other factors in addition to implant diameter.

It is suggested that the type of material (titanium type $\mathrm{V}$ ) determined the larger compressive strength of group G2.8-AA because of the presence of aluminum and vanadium in its composition. The implant's internal profile on the region where the intermediary abutment is coupled to the implant can also be considered because the threads (friction system) can represent weakness areas and increased the risk of fracture. Another possible reason is related to the fact that G2.8-AA abutment is more robust and has no thread, forming a more efficient coupling with the implant.

Qualitative analysis using micro-CT aimed to explain the differences in compressive strength between the groups, since it allows the visualization of different failure patterns. It was possible to observe that G3.5-UAC, despite its larger diameter, showed plastic deformation of the assembly (without TMC) in the presence of a gap at the interface abutment/implant and larger displacement of abutment/ crown with the compression tests. In addition to the plastic deformation, the prosthetic abutment within the implant showed fractures, which can be explained by the implant's design and abutment's composition. The narrow cervical wall of the implant associated with the thin apical portion of the prosthetic abutment in this group might have been a determinant factor to the failure pattern observed in this group. The two-pieces abutment developed by the manufacturer for this implant of $\emptyset 3.5 \mathrm{~mm}$ can be one of the causes for the assembly's weakness given the volumetry of the metallic component structures. Moreover, the use of a fixation screw of this system, instead of a solid abutment, might have made it more prone to failure comparing to other groups.

The difference in composition of abutment/implant or one-piece associated with the external hexagonal prosthetic connection seems to have influenced the results. The group G2.5-HP (one-piece) showed a different failure pattern from other groups, with a minimal plastic deformation of the implant and fracture of the prosthetic component area (equivalent to the abutment) after the compression test. This might have been caused by the force applied by the prosthetic screw against the abutment (lever arm), a particularity of external hexagonal connection, where the prosthetic abutment does not fit the interior of the implant, making the assembly more susceptible to failures (6). The volumetry of this implant of $\emptyset 2.5 \mathrm{~mm}$ with a platform of $\emptyset 3.0 \mathrm{~mm}$ can explain its weakness. Comparing results with and without TMC, we observe an influence of TMC on compressive strength, with reduction for all groups, with statistical significance only for group G2.5-HP. The micro-CT images corroborated this result, showing plastic deformations in all groups.

Correlating clinical expectations regarding masticatory forces with our results, we suggest that all groups can have satisfactory responses to rehabilitations with implantsupported prostheses limited to the region of mandibular central and lateral incisors, and maxillary lateral incisors, given that the maximum loads defined for these regions are between $186 \mathrm{~N}$ and $231 \mathrm{~N}(26)$. The assemblies studied here presented average strength above $300 \mathrm{~N}$, even after TMC.

Based on the results obtained in this study, it is possible to conclude that: compressive strength is different among the tested assemblies and showed no direct relation with the implant diameter, suggesting an influence of the implant alloy (favorable to titanium alloy grade $V$ ) and type of implant/abutment fitting (friction implant - without internal threads); the tested assemblies are not affected by the thermomechanical cycling in regards to vertical marginal adaptation, but the internal misfits are reduced for all the systems; thermomechanical cycling affects the compressive strength of the assemblies, with greater influence over the narrower one $(\varnothing 2.5 \mathrm{~mm})$.

\section{Resumo}

0 objetivo deste estudo foi avaliar a adaptação marginal e interna de cópings metálicos em pilares sobre implantes, e a resistência a fratura de diferentes conjuntos de implantes/pilares de diâmetro reduzido, submetidos à ciclagem termomecânica ou não. Sessenta e quatro implantes/pilares $(n=16)$ foram divididos em 04 grupos de acordo com o tipo de pilar e diâmetro do implante: G3.5-UAC (implante cone morse $\emptyset 3.5 \mathrm{~mm}$ + munhão universal com término em chanfro); G2.9-UAS (implante cone morse $\emptyset 2.9 \mathrm{~mm}+$ munhão universal com término em ombro); G2.8-AA (implante cone morse friccional $\emptyset 2.8 \mathrm{~mm}+$ munhão anatômico); e G2.5-HP (implante de corpo único de $\emptyset 2.5 \mathrm{~mm}$ com plataforma hexagonal indexada). Cada grupo foi dividio em dois subgrupos $(n=8)$ : submetidos ou não à ciclagem termomecânica (TMC). As amostras foram escaneadas por microtomografia (micro-CT) para avaliar a adaptação interna e marginal vertical dos copings metálicos. As amostras foram submetidas à resistência à compressão em uma maquina de ensaios universal. 0 grupo G3.5-UAC apresentou os maiores valores de desadaptação marginal independentemente da TMC $(p<0,05)$. Todos os outros grupos foram similares entre si após TMC. 0 grupo G2.8-AA demonstrou o menor desajuste interno independentemente de TMC $(\mathrm{p}<0,05)$. 0 grupo G2.8-AA demonstrou a maior resistência à fratura, similar apenas ao grupo G2.5-HP sem TMC e G3.5-UAC com TMC. 0 tipo de pilar influencia a adaptação interna e marginal vertical de copings 
metálicos. 0 grupo do pilar anatômico (sem entalhes na superfície) levou à melhor adaptação, enquanto o grupo com plataforma expandida hexagonal e os grupos com munhão universal (com entalhes na superficie) proporcionaram os maiores desajustes (especialmente com termino em chanfro). Os implantes/pilares de diâmetro reduzido diferem em termos de resistencia à fratura, sendo que o conjunto mais resistente foi aquele composto por titânio tipo $\mathrm{V}$ e sem roscas internas (implante friccional).

\section{Acknowledgements}

The authors wish to thank to Dr Adriana Claudia Lapria Faria of the Laboratory of Biomechanical Studies in Prosthodontics and Implants at the Department of Dental Materials and Prosthodontics, School of Dentistry of Ribeirão Preto, University of São Paulo (FORP-USP), Brazil for technical supports. The authors would like to thank to implant companies Neodent, DSP Biomedical and SIN for the donation of material for the execution of the present study.

\section{References}

1. Hirata R, Bonfante EA, Anchieta BR, Machado LS, Freitas G, Fardin VP, et al. Reliability and failure modes of narrow implant systems. Clin Oral Invest 2016;20:1505-1513.

2. Quirynem M, Al-Nawas B, Meijer HJ, Razavi A, Reichert TE, Schimmel $M$, et al. Small-diameter titanium Grade IV and titanium-zirconium implants in edentulous mandibles: three-year results front a doubleblind, randomized controlled trial. Clin Oral Implants Res 2015;26:831840.

3. Bordin D, Witek L, Fardin VP, Bonfante EA, Coelho PG. Fatigue failure of narrow implants with different implant-abutment connection designs. J Prosthodont 2018;27:659-664.

4. Qian J, Wennerberg A, Albrektsson T. Reasons for marginal bone loss around oral implants. Clin Implant Dent Relat Res 2012;14:792-807.

5. Isidor F. Influence of forces on peri-implant bone. Clin Oral Implants Res 2016;17:8-18.

6. Coppedê AR, Bersani E, Mattos MG, Rodrigues RC, Sartori IA, Ribeiro RF. Fracture resistance of the implant-abutment connection in implants with internal hex and internal conical connections under oblique compressive loading: an in vitro study. Int J Prosthodont 2009;22:283286.

7. Bonfante EA, Almeida EO, Lorenzoni FC, Coelho PG. Effects of implant diameter and prosthesis retention system on de reliability of single crowns. Int J Oral Maxillofac Implants 2015;30:95-101.

8. Freitas Jr AC, Bonfante EA, Martins LM, Silva NRFA, Marotta L, Coelho PG. Effect of implant diameter on reliability and failure modes of molar crowns. Int J Prosthodont 2011;24:557-561,

9. Almeida EO, Freitas Junior AC, Bonfante EA, Rocha EP, Silva NR, Coelho PG. Effect of microthread presence and restoration design (screw versus ce-mented) in dental implant reliability and failure modes. Clin Oral Implants Res 2012;24:191-196.

10. Fenner N, Hämmerle CHF, Sailer I, Jung RE. Long-term clinical, technical, and esthetic outcomes of all-ceramic vs. titanium abutments on implant supporting single-tooth reconstruction after at least 5 years. Clin Oral Implants Res 2016;27:716-723.

11. Kahramanoglu E, Kulak-Ozkan Y. Marginal and internal adaptation of different superstructure and abutment materials using two different implant systems for five-unit implant-supported fixed dental prosthesis: an in vitro study. Int J Oral Maxillofac Implants 2016;28:1207-1216.

12. Abduo J, Bennani V, Waddell N, Lyons K, Swain M. Assessing the fit of implant fixed prostheses: a critical review. Int J Oral Maxillofac Implants 2010;25:506-515.

13. Brånemark PI. Osseointegration and its experimental background. J Prosthet Dent 1983;50:399-410.

14. Jemt T. Failures and complications in 391 consecutively inserted fixed prostheses supported by Brånemark implants in edentulous jaws: a study of treatment from the time of prosthesis placement to the first annual checkup. Int J Oral Maxillofac Implants 1991;6:270-276.

15. Katsoulis J, Mericske-Stern R, Enkling N, Katsoulis K, Blatz MB. In vitro precision of fit of computer-aided designed and computer-aided manufactured titanium screw-retained fixed dental prostheses before and after ceramic veneering. Clin Oral Implants Res 2015;26:44-49.

16. Jemt $\mathrm{T}$, Book K. Prosthesis misfit and marginal bone loss in edentulous implant patients. Int J Oral Maxillofac Implants 1996;11:620-625.

17. Khaisat $A$, Stegaroi $R$, Nomura $S$, Miyakawa 0 . Fatigue resistance of two implant/abutment joint designs. J Prosthet Dent 2002;88:604-610.

18. Vásquez VZ, Oskan M, Kimpara ET. Evaluation of interface characterization and adhesion of glass ceramics to commercially pure titanium and gold alloy after thermal and mechanical loading. Dental Mater 2009;25:221-231.

19. Beuer $F$, Aggstaller $H_{1}$ Edelhoff $D$, Gernet W, Sorensen J. Marginal and internal fits of fixed dental prostheses zirconia retainers. Dent Mater 2009;25:94-102.

20. Bauer JR, Grande RH, Rodrigues-Filho LE, Pinto MM, Loguercio AD. Does the casting mode influence microstructure, fracture and properties of different metal ceramic alloys? Braz Oral Res 2012;26:190-196.

21. Moris IC, Faria ACL, Ribeiro RF, Rodrigues RCS. Abutments with reduced diameter for both cement and screw retentions: analysis of failure modes and misfit of abutment-crown-connections after cyclic loading. Clin Oral Implants Res 2017;28:432-436.

22. Wang $H$, Feng $\mathrm{Q}, \mathrm{Li} N, \mathrm{X}$ U S. Evaluation of metal-ceramic bond characteristics of three dental $\mathrm{Co}-\mathrm{Cr}$ alloys prepared with different fabrication techniques. J Prosthet Dent 2016;116:916-923.

23. Kano SC, Bonfante G, Hussne R, Siqueira AF. Use of base metal casting alloys for implant framework: marginal accuracy analysis. J Appl Oral Sci 2004;12:337-343.

24. Kohorst $P$, Junghanns J, Dittmer MP, Borchers L, Stiesch M. Different CAD/CAM processing routes for zirconia restorations: influence on fitting accuracy. Clin Oral Investig 2011;15:527-536.

25. Hecker, DM, Eckert SE. Cyclic loading of implat-supported prostheses: changes in component fit over time. J Prosthet Dent 2003;89:346-351.

26. Serra CM, Manns AE. Bite force measurements with hard and soft bite surfaces. J Oral Rehabil 2013;40:563-568. 